\title{
Rhabdomyolysis in Acute Primary Adrenal Insufficiency Complicated by Severe Hyponatraemia
}

\author{
Su Yin Lau ${ }^{1,3}$ and Tuck Yean Yong ${ }^{2,3}$
}

\begin{abstract}
Patients with acute adrenal insufficiency may have musculoskeletal symptoms including flexion contractures, myopathy and hyperkalaemic neuromyopathy. However, the association between rhabdomyolysis and acute adrenal insufficiency is extremely rare and has only been reported infrequently in the literature. Hyponatraemia is often present in association with acute adrenal insufficiency complicated by rhabdomyolysis. We herein report the case of a patient with acute primary adrenal insufficiency and severe hyponatraemia complicated by rhabdomyolysis and acute kidney injury.
\end{abstract}

Key words: Addison's disease, adrenal insufficiency, creatine kinase, hyponatraemia, rhabdomyolysis

(Intern Med 51: 2371-2374, 2012)

(DOI: 10.2169/internalmedicine.51.7879)

\section{Introduction}

Hyponatraemia is known to occur in patients with adrenal insufficiency, but it is rare for both or either disorder to be concurrently associated with rhabdomyolysis. The aetiology of rhabdomyolysis can be traumatic or non-traumatic. The causes of non-traumatic rhabdomyolysis may include defects in skeletal muscle metabolism, electrolyte disturbances, alcohol intoxication, illicit drug use, infections and medications (eg lipid-lowering agents, antipsychotics) (1). Severe rhabdomyolysis can, in turn, lead to acute kidney injury. Acute adrenal insufficiency can be associated with various musculoskeletal abnormalities, but the association with rhabdomyolysis is extremely uncommon $(2,3)$. This report describes a case of acute primary adrenal insufficiency in association with both severe hyponatraemia and rhabdomyolysis.

\section{Case Report}

A 40-year-old woman presented to a tertiary referral hospital with acute confusion following a three-day history of an upper respiratory tract infection. Her medical history included premature ovarian failure diagnosed six years prior to this presentation. Her only regular medication was $1 \mathrm{mg}$ oestradiol combined with norethisterone (0.5 mg daily). Prior to the hospital admission, she was noted to be increasingly disorientated, had been vomiting, but no seizure activity witnessed.

On examination at presentation, the patient was drowsy (Glasgow Coma Scale of 12) and tachycardic with a blood pressure of $80 / 40 \mathrm{mmHg}$. She had signs of hypovolaemia but no mucosal pigmentation. On the day following admission, the examination did not reveal any neuromuscular abnormalities to suggest a myopathic process or neurological deficit. The rest of her physical examination was normal.

The patient's laboratory tests revealed the following: serum sodium, $106 \mathrm{mmol} / \mathrm{L}$ (135-145); potassium, $4.9 \mathrm{mmol} / \mathrm{L}$ (3.2-4.3); creatinine, $39 \mu \mathrm{mol} / \mathrm{L}$ (45-85); and glucose, 5.4 $\mathrm{mmol} / \mathrm{L}$ (3.0-6.0). The serum and urine osmolality were 228 mosmol/kg (280-300) and $78 \mathrm{mosmol} / \mathrm{kg}$ respectively. Her urinary sodium was $10 \mathrm{mmol} / \mathrm{L}$. The complete blood count and arterial blood gas values were normal. Thyroid function tests, electrocardiography, chest X-ray and head CT scans were normal. The patient was transferred to the intensive care unit for initial management and close monitoring.

Stimulation tests showed no appropriate increase in the cortisol level after administration of $1 \mathrm{mg}$ tetracosactrin (Synacthen), which was $162 \mathrm{nmol} / \mathrm{L}$ at baseline, $164 \mathrm{nmol} / \mathrm{L}$ at 30 minutes, and $175 \mathrm{nmol} / \mathrm{L}$ at 60 minutes after stimulation.

\footnotetext{
${ }^{1}$ Department of Gastroenterology, Flinders Medical Centre, Australia, ${ }^{2}$ Department of General Medicine, Flinders Medical Centre, Australia and ${ }^{3}$ Faculty of Health Science, Flinders University, Australia Received for publication April 3, 2012; Accepted for publication June 10, 2012 Correspondence to Dr. Tuck Y Yong, tuck.yong@ health.sa.gov.au
} 


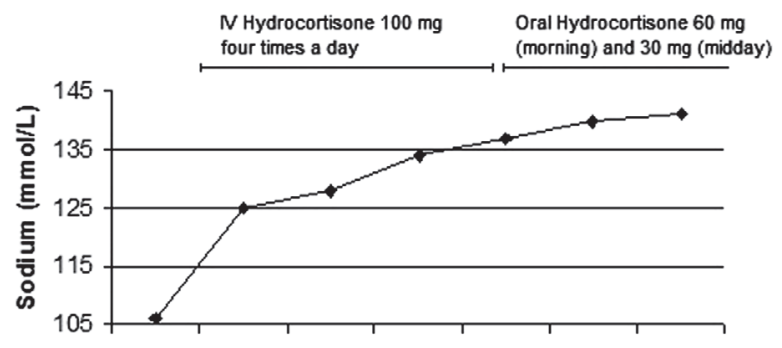

dSDNA), rheumatoid factor (RF), antineutrophil cytoplasmic antibodies (ANCA), and extractable nuclear antigens (ENA) was normal. Serological tests for cytomegalovirus, EpsteinBarr virus, herpes simplex virus types 1 and 2, coxsackie virus, adenovirus and Mycoplasma pneumoniae were all negative. The qualitative anti-adrenal auto-antibody test was positive, suggestive of an autoimmune aetiology for adrenal insufficiency.

The patient was first managed with intravenous hydrocor-
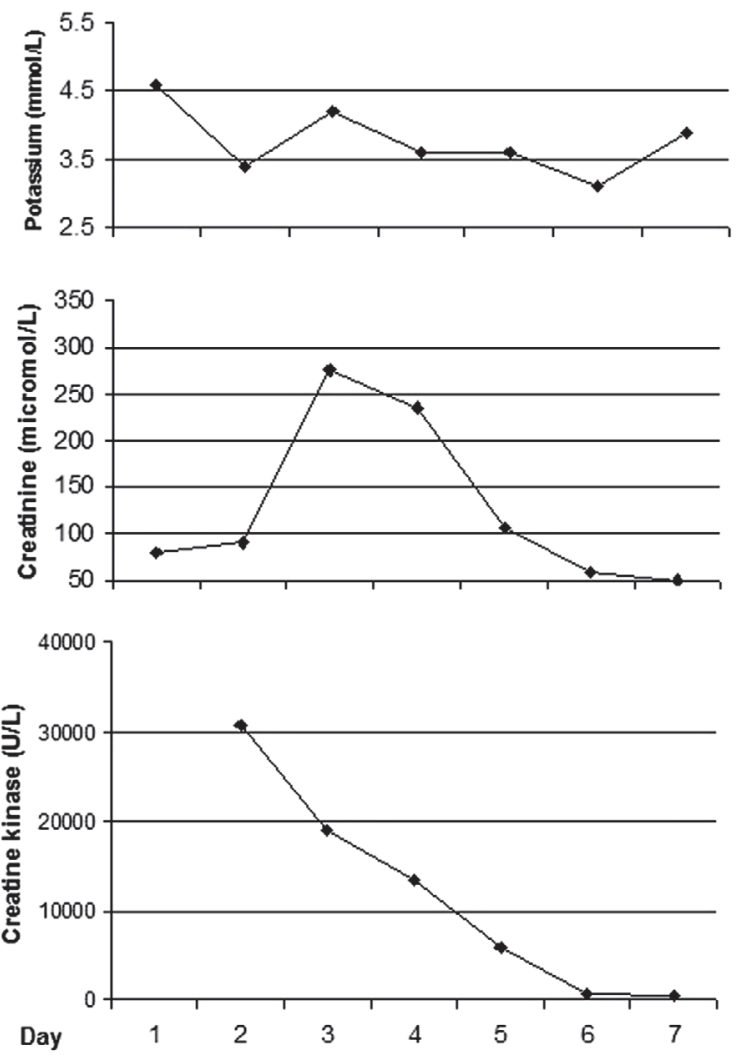

Figure. The changes in the serum sodium, potassium, creatinine and creatine kinase levels between Days 1 and 7 of admission.

An elevated Adrenocorticotrophic hormone (ACTH) level of $832 \mathrm{ng} / \mathrm{L}$ (10-60) was measured at baseline. The plasma aldosterone and direct renin values were $<30 \mu \mathrm{mol} / \mathrm{L}$ (110$860)$ and $46 \mu \mathrm{U} / \mathrm{mL}$ (4-40), respectively, measured in the supine position. These findings were consistent with primary adrenal insufficiency.

On the second day of admission, the patient's creatine kinase $(\mathrm{CK})$ level was incidentally found to be elevated to $30,779 \mathrm{U} / \mathrm{L}(<150)$ and the muscle subunits (MB)-fraction was $22 \mu \mathrm{g} / \mathrm{L}(<7)$, giving a CK-MB fraction of $<0.001 \%$ which indicated a non-cardiac source of the abnormal value. Her aspartate transaminase (AST) level was also mildly elevated, at $503 \mathrm{IU} / \mathrm{L}(<40)$. However, myoglobinuria was not detected in this patient. As a consequence of rhabdomyolysis, she developed acute kidney injury, with the creatinine level rising to a peak of $275 \mu \mathrm{mol} / \mathrm{L}$ and a corresponding estimated glomerular filtration rate (eGFR) of $17 \mathrm{~mL} / \mathrm{min} /$ $1.73 \mathrm{~m}^{2}$. Autoimmune screening was done, including antinuclear antibodies (ANA), anti-double-stranded DNA (antitisone at $100 \mathrm{mg}$ four times a day after confirmation of adrenal insufficiency with the tetracosactrin stimulation test. Intravenous fluids (hypertonic saline at a rate of $40 \mathrm{~mL} / \mathrm{hr}$ initially) was also administered and continued until normalization of the creatinine and CK levels, which occurred on days 4 and 7, respectively, after admission (Figure). The patient did not require haemodialysis throughout her stay in the hospital for treatment of acute kidney injury. Upon stabilization, she was placed on maintenance hydrocortisone therapy at $20 \mathrm{mg}$ in the morning, $10 \mathrm{mg}$ at midday, and fludrocortisone at $0.05 \mathrm{mg}$ daily.

\section{Discussion}

Rhabdomyolysis is associated with many conditions, but is rarely reported in association with acute adrenal insufficiency (2). Rhabdomyolysis has occasionally been reported in the setting of hyponatraemia, and in most cases, this association resulted from water intoxication. Rhabdomyolysis associated with acute primary adrenal insufficiency has only been described in six other cases (Table) (3-8). Table summarizes the clinical and biochemical data in these cases.

All cases reported so far, including the present case, had primary adrenal insufficiency. One case had an episode of convulsions prior to presentation, and this is likely to have contributed to the elevated CK. The CK levels in the cases ranged from 438 to $30,779 \mathrm{U} / \mathrm{L}$, with our case having the highest reported CK level. The majority of cases had hyponatraemia, with the lowest sodium concentration reported as $97 \mathrm{mmol} / \mathrm{L}(5)$. In one case, rhabdomyolysis was observed with adrenal insufficiency in the absence of hyponatraemia (6). The potassium concentrations were above the reference range in four cases, the highest reported being 5.8 $\mathrm{mmol} / \mathrm{L}$.

The acute kidney injury most likely a consequence of the rhabdomyolysis, as described in our case, but this injury was only reported in one other case. In this other case, there were other potential confounding factors, such as the use of an angiotensin converting enzyme inhibitor, which may have contributed to the acute kidney injury (4).

Rhabdomyolysis has been reported in the setting of other causes of hyponatraemia, such as water intoxication and syndrome of inappropriate secretion of antidiuretic hormone (SIADH) $(9,10)$. The degree of hyponatraemia has yet to be correlated with the incidence or severity of rhabdomyolysis. Acute kidney injury is a common complication of rhabdomyolysis, with an incidence of $46 \%$ in one study (11). 
Table. Summary of Clinical and Biochemical Data of Patients with Rhabdomyolysis and Acute Primary Adrenal Insufficiency

\begin{tabular}{|c|c|c|c|c|c|c|c|}
\hline References & $\begin{array}{l}\text { Age/ } \\
\text { Sex }\end{array}$ & Seizure & $\begin{array}{c}\text { Sodium } \\
(\mathrm{mmol} / \mathrm{L})\end{array}$ & $\begin{array}{c}\text { Potassium } \\
(\mathrm{mmol} / \mathrm{L})\end{array}$ & $\begin{array}{c}\text { Urea } \\
(\mathrm{mmol} / \mathrm{L})\end{array}$ & $\begin{array}{c}\text { Creatinine } \\
(\mu \mathrm{mol} / \mathrm{L})\end{array}$ & $\begin{array}{c}\text { Peak CK } \\
(\mathrm{U} / \mathrm{L})\end{array}$ \\
\hline Mor et $\mathrm{al}^{3}$ & $44 / \mathrm{F}$ & Absent & 103 & 5.0 & Normal* & Normal* & 1,670 \\
\hline Jolobe et $\mathrm{al}^{4}$ & $81 / \mathrm{F}$ & Absent & 138 & 4.7 & 26.0 & 225 & 3,338 \\
\hline Egan et $\mathrm{al}^{5}$ & $63 / \mathrm{F}$ & Absent & 97 & 5.8 & 4.7 & 50 & 21,490 \\
\hline de Witte et al ${ }^{6}$ & $48 / \mathrm{M}$ & Absent & Normal* & Normal* & Normal* & Normal* & 438 \\
\hline Oki et $\mathrm{al}^{7}$ & $52 / \mathrm{M}$ & Present & 118 & 3.7 & NR & NR & 11,902 \\
\hline Solter et $\mathrm{al}^{8}$ & $33 / \mathrm{M}$ & Absent & 125 & NR & NR & NR & 12,560 \\
\hline Current case & $40 / \mathrm{F}$ & Absent & 106 & 4.9 & 9.0 & 275 & 30,779 \\
\hline
\end{tabular}

*Absolute values were not provided in these reports.

NR: not recorded

Therefore, the present and other cases indicate that the CK levels should be measured in patients presenting with acute adrenal insufficiency complicated by hyponatraemia.

In the absence of hyponatraemia-associated seizures, the mechanism of rhabdomyolysis in the setting of hyponatraemia is unclear. One possible mechanism is muscle cell lysis resulting from cellular oedema caused by the diffusion of water across the cell membrane as the extracellular fluid osmolality falls (12). Another postulated mechanism is the activation of $\mathrm{Na} / \mathrm{Ca}$ exchange, causing an increase in intracellular calcium, which in turn leads to disruption of the skeletal muscle (13). Seizures as a result of hyponatraemia can cause muscle damage and a rise in the CK level, but seizure activity was only present in one of the cases, and was not present in our case (7). Correction of severe hyponatraemia has also been suggested as a possible cause of rhabdomyolysis, but in some cases, the rise in the CK level was observed a few days after correcting the electrolyte disturbance (14). The pathophysiology of rhabdomyolysis in hyponatraemia and acute adrenal insufficiency is still not fully understood.

Myalgia is a common symptom of cortisol deficiency, and various skeletal muscular symptoms can be the presenting feature of adrenal insufficiency (2). Although not seen in the present case, flexion contracture is occasionally observed in patients with adrenal insufficiency (15). One patient with rhabdomyolysis in the setting of acute primary adrenal insufficiency had a skeletal muscle biopsy which revealed only non-specific myositis with moderate lymphocytic infiltration (8). The mechanism underlying the potential relationship between cortisol deficiency and rhabdomyolysis is unknown.

Hyponatraemia in acute adrenal insufficiency can be attributed to both cortisol and aldosterone deficiency (16). Cortisol deficiency increases the corticotrophin-releasing hormone level, which stimulates anti-diuretic hormone $(\mathrm{ADH})$ release, resulting in hyponatraemia. Aldosterone deficiency causes hyponatraemia by renal sodium loss, hypovolaemia, and baroreceptor-mediated ADH release.

This case demonstrated an unusual concurrent presentation of acute adrenal insufficiency, severe hyponatraemia and rhabdomyolysis complicated by acute kidney injury. This case emphasizes the importance of recognising rhabdomyolysis in acute adrenal insufficiency complicated by severe hyponatraemia so that appropriate treatment can be instituted to prevent the occurrence of progressive kidney injury.

\section{The authors state that they have no Conflict of Interest (COI).}

\section{References}

1. Gabow PA, Kaehney WD, Kelleher SP. The spectrum of rhabdomyolysis. Medicine 61: 141-152, 1982.

2. Shapiro MS, Trebich C, Shilo L, Shenkman L. Myalgias and muscle contractures as the presenting signs of Addison's disease. Postgrad Med J 64: 222-223, 1988.

3. Mor F, Green P, Wysenbeek AJ. Myopathy in Addison's disease. Ann Rheum Dis 46: 81-83, 1987.

4. Jolobe O, Sen I. Hyponatraemic rhabdomyolysis in Addison's disease. Postgrad Med J 71: 574, 1993.

5. Egan JJ, Davies AJ, Jones MK. Hyponatraemic rhabdomyolysis in Addison's disease. Postgrad Med J 70: 830-832, 1994.

6. de Witte SA, Bonnet F, Morlat P, Beylot J. Rhabdomyolysis as a consequence of adrenal insufficiency. Am J Med 114: 160, 2003.

7. Oki K, Noda K, Kondo K, Koide J. Rhabdomyolysis associated with hyponatremia and adrenal insufficiency. Eur J Neurol 13: e8e9, 2006.

8. Solter M, Planinc D, Gabrić I, Katalinic D, Vucicević Z. Severe rhabdomyolysis as a first symptom in Addison's disease. J Endocrinol Invest 33: 206-207, 2010.

9. Morita S, Inokuchi S, Yamamoto R, et al. Risk factors for rhabdomyolysis in self-induced water intoxication (SIWI) patients. J Emerg Med 38: 293-296, 2010.

10. Sasaki M, Yuzawa M, Saito T, et al. Clinical and laboratory features of hyponatremia-induced myopathy. Clin Exp Nephrol 11: 283-286, 2007.

11. Melli G, Chaudhry V, Cornblath DR. Rhabdomyolysis: an evaluation of 475 hospitalized patients. Medicine (Baltimore) 84: $377-$ 385,2005

12. Verbalis JG. Hyponatraemia. Ballières Clin Endocrinol Metab 3: 499-530, 1998.

13. Korzets A, Ori Y, Floro S, et al. Case report: severe hyponatremia after water intoxication: a potential cause of rhabdomyolysis. Am J Med Sci 312: 92-94, 1996.

14. Menashe G, Borer A, Gilad J, Horowitz J. Rhabdomyolysis after correction of severe hyponatremia. Am J Emerg Med 18: 229-230, 
Intern Med 51: 2371-2374, 2012 DOI: 10.2169/internalmedicine.51.7879

2000

15. Nishikawa T. Flexion contractures possibly reflect the existence of hypocortisolism. Intern Med 42: 629-631, 2003.
16. van der Hoek J, Hoorn EJ, de Jong GM, Janssens EN, de Herder WW. Severe hyponatremia with high urine sodium and osmolality. Clin Chem 55: 1905-1909, 2009.

(C) 2012 The Japanese Society of Internal Medicine http://www.naika.or.jp/imonline/index.html 